\title{
Editoriali
}

\section{Epidemiological aspects of some problems in child and adolescent psychiatry}

\author{
DAVID SHAFFER
}

The word epidemiology derives from the Greek words epi (upon), demos (people), and logos (the study of), and is often defined (MacMahon \& Pugh, 1970) as the study of how rates of disease vary in differing populations. This strategy has been used to great effect in child psychiatry where epidemiological findings have pointed the way to fundamentally importane knowledge. In this editorial I will make some general points and then focus on how epidemiological research has helped clarify problems in our diagnostic classification systems and has led the way to a clearer understanding of causal mechanisms in adolescent suicide.

One of the most common uses of epidemiology is to study, for administrative purposes, the distribution of disease in different geographical areas. Describing the size and distribution of health problems can inform government on the need for services, where they should be located, and of what they should consist (Costello et al., 1993). However, epidemiology can tell us far more than this, and, providing that associations observed in epidemiological research obey certain rules (e.g., dose-response relationships, appropriate time sequencing. etc.), can

Addres for correspondence: Professor D. Shaffer, Irving Philips Professor of Child Psychiatry, Columbia University, 722 West $168^{\text {th }}$ Street, New York City 10032 (USA).

Fax $+1212-543.5966$

E-mail: shaffer@child.cpmc.columbia.edu be used to infer cause and to point the way to understanding quite precise causal mechanisms.

An example of how epidemiology has provided a road map in child psychiatry lies in Rutter's classic multi-informant, multi-method epidemiological study on the Isle of Wight (Rutter, 1989; Rutter et al., 1970). In that study it was apparent that the structure and behavior of families of children with conduct disorder was different from those without. Conduct-disordered children were more likely to have broken homes, their care was more likely to have been interrupted and their parents were more likely to have unhappy marriages or relationships. Epidemiological findings like this gave impetus to a great volume of research - focussed epidemiological and follow-up investigations, direct observational studies, animal experimentation, etc. - into the ways in which family disruption might lead to antisocial behavior. Taken together, they have led to the currently favored conclusion that the causes of antisocial behavior lie in situations that work against the development of a close relationship between parents and child (Sampson \& Laub, 1996), which is in turn leading to very specific prevention strategies (Wasserman \& Miller, 1998).

\section{EPIDEMIOLOGY AND CLASSIFICATION}

Epidemiological studies classically involve a distinctive approach to sampling and sample descrip- 


\section{Shaffer}

tion such that the population under study is carefùlly defined with respect to other populations. This allows epidemiologists to compare one study with another and it can allow investigators to determine whether discrepancies between studies are due to some fundamental difference or to sample variation (Rutter et al., 1975). This attention to sampling and to sample description has, over the years, informed us of the biases that are present in many populations that are convenient for research but that may be quite inappropriate for describing the characteristics of a disorder. The instinct of many clinician-researchers is to study a group of patients drawn from their own clinic or hospital. However, they should be cautious about this, because community based studies show that there are many families and children with even quite severe psychiatric symptoms or disorders who do not get referred for care (Mitchell \& Shepherd, 1966) and that those who do, differ in fundamental ways from those who do not (Cohen \& Cohen, 1984). For example, symptomatic patients are more likely to have parents with a psychiatric illness and more often have multiple diagnoses than similar children who do not attend a clinic.

The criterion-based DSM systems (American Psychiatric Association, 1980; 1987; 1994) originated with the opinions of experts who met together and agreed on the defining descriptive characteristics of various diagnoses. However, the source of their wisdom - for many of the psychiatric disorders of children - was most often rooted in clinical experience rather than empirical observation. They were, therefore, being informed by the biased samples that are seen and studied by clinicians. This bias may give rise to misleading descriptions of clinical entities. This was illustrated in the MECA epidemiological study (Lahey et al., 1996) which provided systematic information on the prevalence of DSM-IIIR symptoms.

In the MECA study, the presence of all of the symptoms that were required for DSM-IIIR diagnoses was ascertained in 1200 non-referred children along with a measure of social and academic impairment and subjective distress (Shaffer el al., 1996b). Surprisingly, it was found that a high proportion of children met full symptomatic criteria for a diagnosis but were apparently doing well in their relationships with their families, were well-adjusted at school, had friends, and were experiencing no subjective distress. These findings that could only have emerged in epidemiological research, prompted the
American Psychiatric Association (1994) to decide that, even if an individuai shows all of the symptoms required by DSM for a diagnosis, they should not be regarded as suffering from a psychiatric illness, unless they also experience some form of interpersonal, occupational, or academic impairment or subjective distress. Psychiatry, therefore, had been directed into a situation that is quite unlike that found in any of the medical specialities in which disorders cari be present - and often are - without causing distress or impairment. On some level, this is an untenabie situation but one must assume that it will ultimately stimulate helpful research into the sources of impairment in symptomatic individuals and whether or not the unimpaired differ with respect to experiences and heritability from the symptomatic impaired.

Another way in which epidemiological research is likely to influence classification has been the finding from several epidemiological studies (Anderson et al., 1987, McGee et al., 1990) that a large majority of children with one DSM-IV anxiety disorder, also have another. That is, that there are very high levels of comorbidity between different DSM diagnoses in children and adolescents. Comorbidity is most pronounced between different anxiety disorders, between mood and anxiety disorders, between mood and conduct disorders, and between Attention Deficit Hyperactivity Disorder (ADHD) and Oppositional Defiant Disorder (ODD). Possible explanations for these high rates of comorbidity (Angold \& Costello, 1993) are that similar etiological factors, either biological or environmental - give rise to different diagnostic conditions, or, that one condition gives rise to another, or, most troublingly, that perhaps we have drawn the boundaries of our diagnoses artificially and incorrectly and that, in reality, psychiatric conditions are more complex and polymorphic than is suggested by DSM (Kendier et al., 1998).

A third and related problem that has emerged in the DSM nosology is the issue of diagnostic boundaries. High rates of comorbidity between oppositional defiant disorder and attention deficit hyperactivity disorder raise the question of whether the boundaries between these disorders are real. Our classification systems, upon which so much depends, badly need a carefully designed epidemiological study - free of the bias that pertains to clinical populations - that can determine whether the risk factors (e.g. family history, family structure, early experiences and, ultimately, prognosis) are different be- 
tween different, frequently comorbid disorders or whether the field has been lured by superficial phenomenological differences that do not reflect anything more fundamental than form.

\section{EPIDEMIOLOGY AND YOUTH SUICIDE}

Epidemiological studies have provided the stimulus for much new knowledge on the problem of adolescent suicide.

Mortality data drawn from many different countries revealed that the suicide rate among young people had increased steadily between the mid-1960's and the mid 1980's (Fisher \& Shaffer, 1990; Shaffer \& Hicks, 1993). A closer examination of the mortality data showed that the increase mainly affected boys. This stimulated a search for one or more risk factors that: a) were likely to vary over time, and b) operate more powerfully in boys than in girls. In a controlled psychological autopsy study of all adolescent suicides that occurred in the greater New York area (Shaffer et al., 1996a; Gould et al., 1996; 1998) we found such a variable. Substance and alcohol abuse were extremely common in older male adolescents who had committed suicide, but not in females. This finding suggested that the cause of the increase in suicide over the past thirty years could lie in increased exposure to drugs and alcohol. But why should it operate only in boys?

Substance and alcohol abuse rates have been rising in boys and girls alike during this period (Varnik, 1997). This question has not been fully addressed, but it can be tied, quite tantalizingly to observations made on the relationship between abnormalities in the serotonergic system and suicide (Mann, 1998). Base levels of serotonergic function tend to be lower in males than females, and they are adversely affected, i.e. further lowered, by exposure to alcohol. Epidemiological findings have opened an important research trail whose final destination is not yet known.

Another example of how epidemiological observations can lead to a better understanding of the psychopathology of suicide derives from the common observation that suicide rates vary considerably between countries, even between those that have similar political systems and socioeconomic conditions. This variation also occurs within countries. In the United States, African-Americans have significantly lower rates of suicide than Whites or Hispanics (Shaffer \& Hicks, 1993). This is of great interest be- cause it makes it unlikely that suicide is a simple consequence of environmental stress for on almost all, social, educational, and family parameters, AfricanAmericans are less advantaged than their White American compatriots. Could it be that AfricanAmericans were actually being protected from suicide by some factor? Gibbs (1988) had suggested that social support systems are more robust in African-Americans, and Martin (1984) has proposed that African-American fundamentalist religious beliefs offer protection from suicide. Once again, an epidemiological finding stimulated further investigation. The New York Suicide Study was designed to obtain a significant number of African-American teens and controls to study this question. Gould et al. (1996), analyzing data from the study, found that while the socioeconomic status (SES) of White and Hispanic sulcides was similar to the distribution of SES in the general population, this was not the case for African-Americans. The African-American adolescents who committed suicide were better educated and wealthier than African-Americans in the control community. This finding is compatible with the fact that there may be some cultural-psychological factors that protect against suicide for AfricanAmericans, but that, as economic and educational advancement gathers pace, these differences will gradually diminish. In fact, this prediction has been fulfilled for, starting in the late 1980's, the AfricanAmerican teen suicide rate started to increase precipitously (Shaffer $e l$ al., 1994), threatening to intersect with the White rate. As Biack and White cultures have become less distinctive, so have their suicide rates. As education and other cultural factors become more similar between countries, we may therefore expect that there will be a gradual reduction in the differences in the suicide rate between different countries. If we couid better understand the mechanisms that underlie these cultural differences we might be able to apply them for suicide prevention purposes.

Epidemiological research may also be used to confirm or refute detailed observations. In 1974, I reported (Shaffer, 1974) on several suicides that appeared to have taken place immediately after a teenager had completed reading a novel in which the suicide of a young person has figured prominently or, after a news story had been released about a prominent person who had committed suicide. Findings of this kind were found in large epidemiological studies (Phillips, 1974) that showed that news reports of suicide led to a temporary increase in the suicide rate in 


\section{Shaffer}

that community. The increase was proporzionate to the amount of news coverage and was greatest when the suicide was reported in large headlines and was of a well-known person. It was least when the suicide victim was an unknown figure, or when it was reported on inside pages. Other epidemiological research (Gouid \& Shaffer, 1988; Schmldtke \& Häfner, 1986) has shown how the fictional representation of young people's suicide on television can lead to an increase in suicide morbidity, predominantly among young people. Other epidemiological studies on the imitation phenomenon have shown that about $10 \%$ of youth suicides cluster within certain periods and locations (Gould el al., 1990) forming mini epidemics. These findings led, in due course, to the preparation of guidelines for newspaper editors and reporters that have the potential of reducing the suicide rate (Centers for Disease Control, 1988).

A final example drawn from epidemiological studies of suicide has been the recent, encouraging observation that suicide rates in adolescents have started to decline in many different countries (Isaacson \& Bergman, 1998). There are several possible explanations for this. It could simply be a manifestation of a naturai variation in suicide rates with regression to the mean, or it could be the result of the increasing use of low side-effect profile antidepressants (such as the SSRIs) in youth (Olfson et al., 1998). Alternatively, it may be that a decline in drug and alcohol use and abuse rates is reducing the likelihood of alcohol-precipitated suicide. In this field, as in others, epidemiological studies point the way for useful research.

\section{REFERENCES}

American Psychiatric Association (1980). Diagnostic and Statistical Manual of Mental Disorders ( $3^{\text {rd }}$ ed.). American Psychiatric Association: Washington DC.

American Psychiatric Association (1987). Diagnostic and Statistical Manual of Mental Disorders ( $3^{\text {rd }}$ ed. revised). American Psycbiatric Association: Washington DC.

American Psychiatric Association (1994). Diagnostic and Statistical Manual of Mental Disorders ( $4^{\text {th }}$ ed.). American Psychiatric Association: Washington DC.

Anderson J.C., Williams S., McGee R. \& Silva P.A. (1987). DSMIII disorders in preadolescent children: Prevalence in large sample from the general population. Archives of General Psychiatry 44, 69-76.

Angold A. \& Costello E.J. (1993). Depressive comorbidity in children and adolescents: empirical theoretical, and methodological issues. American Journal of Psychiatry 150, 1779-1791.

Brent D.A., Perper J.A., Moritz G., Allman C., Friend A., Roth
C., Schweers J., Balach L. \& Baugher M. (1993). Psychiatric risk factors for adolescent suicide: a case-control study. Journal of the American Academy of Child and Adolescent Psychiatry 32(3), 521-529.

Centers for Disease Control (1988). CDC recommendations for a community plan for the prevention and containment of suicide clusters. Morbidity and Mortality Weekly Report 37(S-6), 1-12.

Cohen P. \& Cohen J. (1984). The clinician's illusion. Archives of General Psvchiatry 41, 1178-1182.

Costello E.J., Burns B.J., Angold A. \& Leaf P.J. (1993). How can epidemiology improve mental health services for children and adolescents? Journal of the American Academy of Child and Adolescent Psychiatry 32, 1106-1113.

Fisher P. \& Shaffer D. (1990). Facts about adolescent suicide. A review of national mortality statistics and recent research. In Planning to Live. Evaluating and Treating Suicidal Teens in Community Settings (ed. M.J. Rotheram-Borus, J. Bradley and N. Obolensky) pp. 3-33. National Resource Center for youth Services: Tulsa (Oklahoma).

Gibbs J.T. (1988). Conceptual, methodological, and sociocultural issues in black youth suicide: implications for assessment and early intervention. Suicide and Life-Threatening Behavior 18, 73-89.

Gould M.S. \& Shaffer D. (1988). The impact of televised movies about suicide. New England Journal of Medicine 318, 707-708.

Gould M.S., Wallenstein S. \& Kleinman M. (1990). Time-spice clustering of teenage suicide. American Journal of Epidemiology 131(1), 71-78.

Gould M.S., Fisher P., Shaffer D., Parides M. \& Flory M. (1996). Psychosocial risk factors of child and adolescent completed suicide. Archives of General Psychiatry 53, 1155-1164.

Gould M.S., Shaffer D., Fisher P. \& Garfinkel R. (1998). Separation/divorce and child and adolescent completed suicide. Journal of the American Academy of Child and Adolescent Psychiatry 37, 156-162.

Isaacson G. \& Berman U. (1998). Does increased use of antidepressants reduce suicide rates. Paper presented at $7^{\text {th }}$ European symposium on Suicide \& Suicidal Behaviour. Gent Belgium. September, 1998.

Kendler K.S., Karkowski L.M. \& Walsh D. (1998). The structure of psychosis: latent class analysis of probands from the Roscommon family study. Archives of General Psychiatry 55, 492-499.

Lahey B.B., Flagg E.W., Bird H.R., Schwab Stone M.E., Canino G., Dulcan M.K., Leaf P.J., Davies M., Brogan D., Bourdon K., Horwitz S.M., Rubio-Stipec M., Freeman D.H., Lechtman J.H., Shaffer D., Goodman S.H., Narrow W.E., Weisman M.M., Kandel D.B., Jensen P.S., Richters J.E. \& Regier D.A. (1996). The NIMH Methods for the Epidemiology of Child and Adolescent Mental Disorders (MECA) Study: background and methodology. Journal of American Academy of Child and Adolescent Psychiatry 35, 855-864.

MacMahon B. \& Pugh T. (1970). Epidemiology: Principles and Methods. Brown and Company: Little.

Mann J.J. (1998). The neurobiology of suicide. Nature Medicine 4(1), 25-30.

Martin W. (1984). Religiosity and United States suicide rates, 1977-1978. Journal of Clinical Psychology 40, 1166-1169.

Mc Gee R., Feehan M., Williams S., Partridge F., Silva P.A. \& Kelly J. (1990). DSM-III disorders in a large sample of adolescents. Journal of American Academy on Child and Adolescent Psychiatry 29, 611-619.

Mitchell S. \& Shepherd M. (1966). A comparitive study of chil- 
dren's behavior at home and school. British Journal of Educational Psychology 36, 348.

Olfson M., Marcus S.C., Pincus H.A., Zito J.M., Thompson J.W. \& Zaron D.A. (1998). Antidepressant prescribing practices of outpatient psychiatrists. Archives of General Psychiatry 55, 310-316.

Phillips D.P. (1974). The influence of suggestion on suicide: substantive and theoretical implication of the Werther effect. American Sociological Review 39, 340-354.

Rutter M. (1989). Isle of Wight revisited: twenty-five years of child psychiatric epidemiology. Journal of American Academy of Child and Adolescent Psychiatry 28, 633.

Rutter M., Tizard J. \& Whitmore K. (1970). Education, Health and Behaviour. Longmans: London.

Rutter M., Cox A., Tupling C., Berger M. \& Yule W. (1975). Attainment and adjustment in two geographical areas. British Journal of Psychiatry 126, 493 -509.

Sampson R.J. \& Laub J.H. (1996). Crime in the Making. Harvard University Press: Cambridge (MA).

Schmidtke A. \& Häfner H. (1986). Die Vermittlung von Selbstmordmotivation and Selbstmordhandlung Durch Fiktivemodelle. Nervenarzt 57, 502-510.

Shaffer D. (1974). Suicide in childhood and early adolescence. Journal of Child Psychology and Psychiatry 15, 275-291.

Shaffer D. \& Hicks R. (193). The epidemiology of child and ado- lescent suicide. In The Epidemiology of Childhood Disorders (ed. B. Pless), pp. 339-368. Oxford University Press: New York.

Shaffer D., Gould M. \& Hicks R. (194). Increasing rate of black suicide in the United States. American Journal of Psychiatry $151,1810-1812$.

Shaffer D., Gould M., Fisher P., Trautman P., Moreu D., Kleinman M. \& Flory M. (1996a). Psychiatric diagnosis in child and adolescent suicide. Archives of General Psychiatry 53, 339-348.

Shaffer D., Fisher P., Dulcan M., Davies M., Piacentini J., Schwab-Stone M., Lahey B., Bourdon K., Jensen P., Bird H., Canino G. \& Regier D. (1996b). The NIMH Diagnostic Interview Schedule for Children (DISC 2): description, acceptibility, prevalences, and performance in the MECA study. Journal of American Academy on Child and Adolescent Psychiatry 35, 865-877.

Varnik A. (1997). Suicide in the Baltic Countries and in the former republics of the USSR. Dissertation published by the Karolinska Institute, Stockholm.

Wasserman G.A. \& Miller L.S. (1990). The prevention of serious and violent juvenile offending. In Serious and Violent Offenders: Risk Factor and Successful Interventions (ed. R. Loeber and D.P. Farrington), pp. 197-247. Sage: Thousand Oaks (CA). 